\title{
Correction: Luo, Y.P. et al., Using Near-Infrared Enabled Digital Repeat Photography to Track Structural and Physiological Phenology in Mediterranean Tree-Grass Ecosystems. Remote Sens. 2018, 10, 1293.
}

\author{
Yunpeng Luo ${ }^{1, * \mathbb{C}}$, Tarek S. El-Madany ${ }^{1}{ }^{\mathbb{D}}$, Gianluca Filippa ${ }^{2}$, Xuanlong Ma ${ }^{1} \mathbb{D}$, \\ Bernhard Ahrens ${ }^{1}$, Arnaud Carrara ${ }^{3}$, Rosario Gonzalez-Cascon ${ }^{4} \oplus$, Edoardo Cremonese ${ }^{2}$, \\ Marta Galvagno ${ }^{2}$, Tiana W. Hammer ${ }^{1}$, Javier Pacheco-Labrador 1,5 ${ }^{(D)}$, M. Pilar Martín ${ }^{5}$, \\ Gerardo Moreno ${ }^{6}(D)$, Oscar Perez-Priego ${ }^{1}$, Markus Reichstein 1,7, Andrew D. Richardson ${ }^{8,9,10}$, \\ Christine Römermann ${ }^{7,11,12}$ (D) and Mirco Migliavacca ${ }^{1}$ \\ 1 Department for Biogeochemical Integration, Max-Planck-Institute for Biogeochemistry, 07745 Jena, Germany; \\ telmad@bgc-jena.mpg.de (T.S.E.-M.); xma@bgc-jena.mpg.de (X.M.); bahrens@bgc-jena.mpg.de (B.A.); \\ thammer@bgc-jena.mpg.de (T.W.H.); jpacheco@bgc-jena.mpg.de (J.P.-L.); opriego@bgc-jena.mpg.de (O.P.-P.); \\ mreichstein@bgc-jena.mpg.de (M.R.); mmiglia@bgc-jena.mpg.de (M.M.) \\ 2 Environmental Protection Agency of Aosta Valley, ARPA Valle d'Aosta, 11020 Aosta, Italy; \\ g.filippa@arpa.vda.it (G.F.); e.cremonese@arpa.vda.it (E.C.); m.galvagno@arpa.vda.it (M.G.) \\ 3 Fundación Centro de Estudios Ambientales del Mediterráneo (CEAM), 46980 Paterna, Spain; \\ arnaud@ceam.es \\ 4 Department of Environment, National Institute for Agriculture and Food Research and Technology (INIA), \\ 28040 Madrid, Spain; cascon@inia.es \\ 5 Environmental Remote Sensing and Spectroscopy Laboratory (SpecLab), Institute of Economic, \\ Geography and Demography (IEGD-CCHS), Spanish National Research Council (CSIC), \\ 28037 Madrid, Spain; mpilar.martin@cchs.csic.es \\ 6 Institute for Dehesa Research, University of Extremadura, 10600 Plasencia, Spain; gmoreno@unex.es \\ 7 Michael-Stifel-Center Jena for Data-driven and Simulation Science, 07743 Jena, Germany; \\ christine.roemermann@uni-jena.de \\ 8 Department of Organismic and Evolutionary Biology, Harvard University, Cambridge, MA 02138, USA; \\ andrew.richardson@nau.edu \\ 9 School of Informatics, Computing and Cyber Systems, Northern Arizona University, \\ Flagstaff, AZ 86011, USA \\ 10 Center for Ecosystem Science and Society, Northern Arizona University, Flagstaff, AZ 86011, USA \\ 11 Institute of Ecology and Evolution, Plant Biodiversity Group, Friedrich Schiller University Jena, \\ 07743 Jena, Germany \\ 12 German Centre for Integrative Biodiversity Research (iDiv) Halle-Jena-Leipzig, D-04103 Leipzig, Germany \\ * Correspondence: yluo@bgc-jena.mpg.de; Tel.: +49-364-757-6208
}

Received: 20 March 2019; Accepted: 25 March 2019; Published: 26 March 2019

The authors modify the schematic plots in their article [1] showing the instrument set-ups in the graphical abstract and Figure 1 because the layout of the instrument set-up is not free of copyright and it was not properly cited [2]. In order to avoid any copyright infringements in the future, the schematic plots of the instruments in both the graphical abstract and Figure 1 have now been changed in the corrected version of the paper. The caption of Figure 1 has also been updated (page 4 of the paper). 
Old graphical abstract:

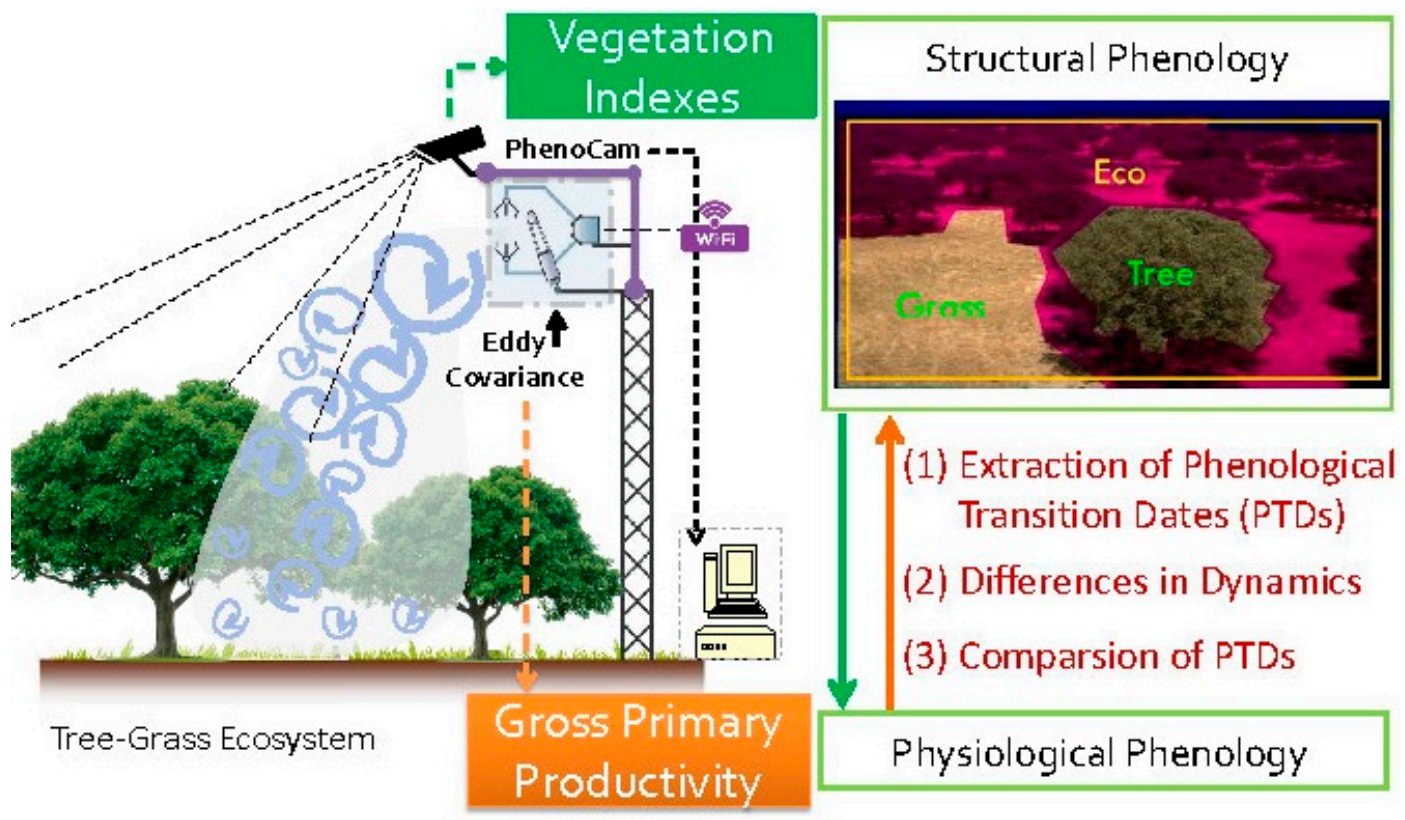

Revised graphical abstract:
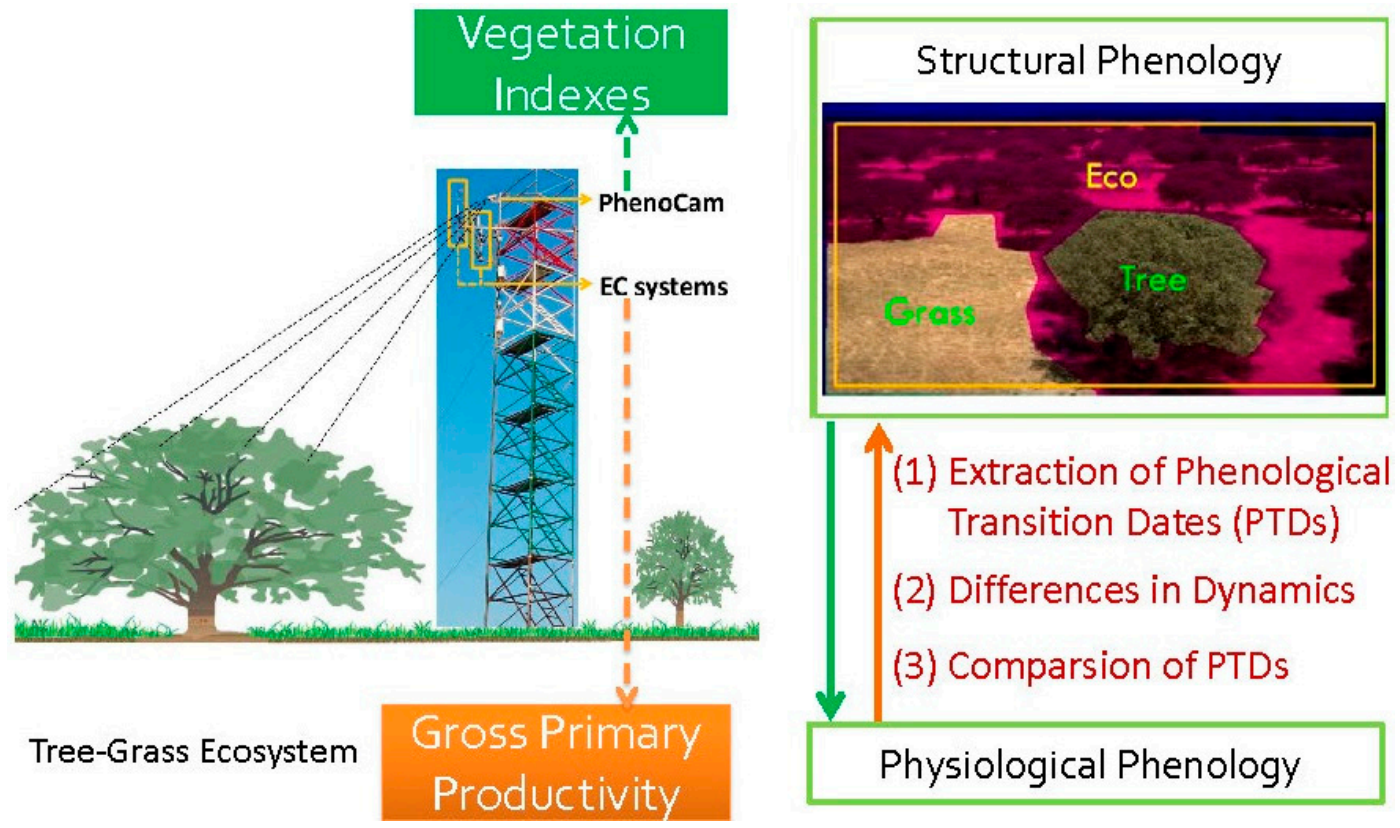
Old Figure 1 and its caption:
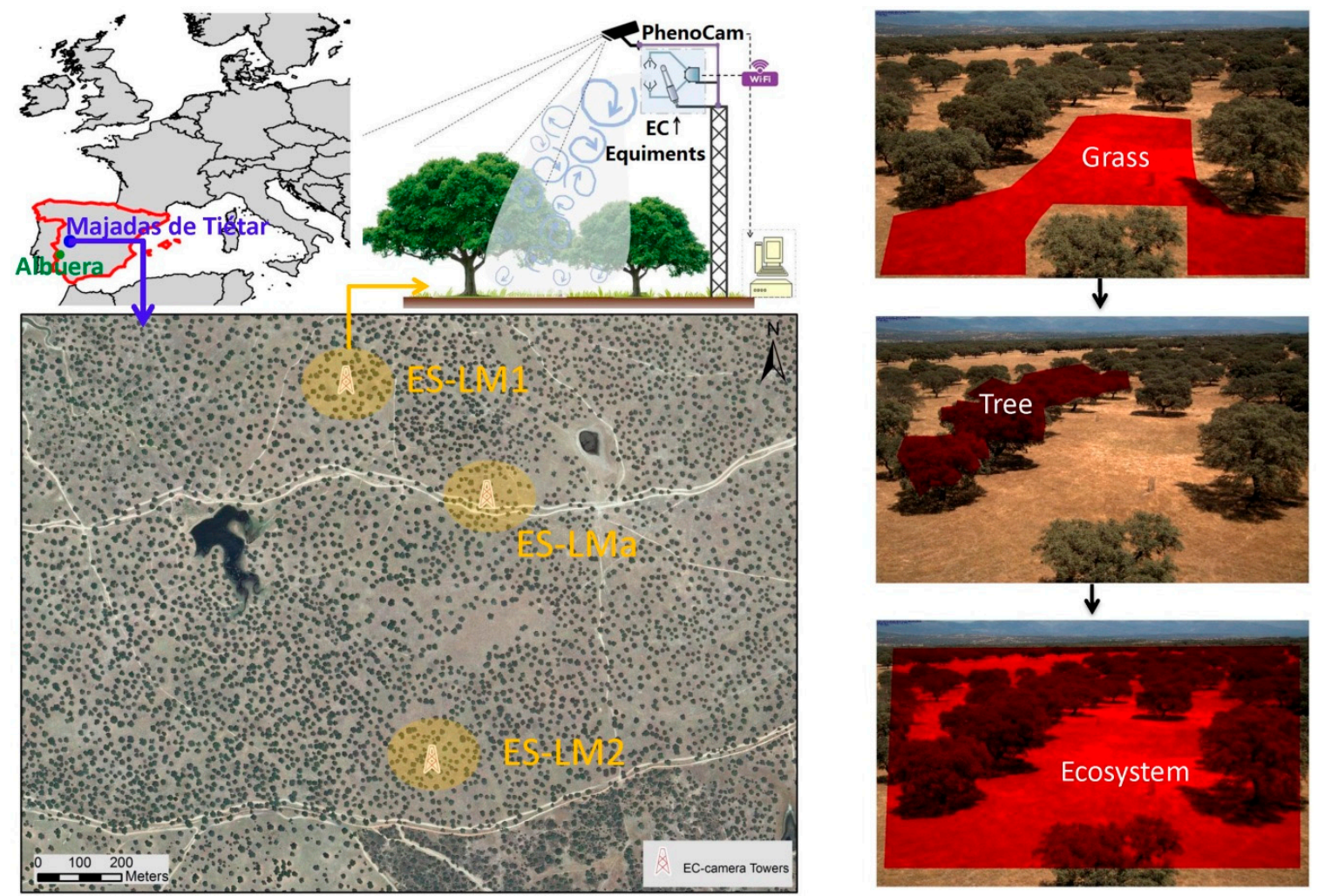

Figure 1. Experimental setup at Majadas de Tiétar and La Albuera in the Spain (left panel) and an example of regions of interest (ROIs) in each experimental site (right panel): Grass, Tree, and Ecosystem ROIs, respectively. At each site, an eddy covariance (EC) system was installed at a height of $15 \mathrm{~m}$ to measure the fluxes of the whole ecosystem. A near-infrared-enabled camera was installed at $15 \mathrm{~m}$ beside the EC system to take pictures half-hourly between 10:00 and 14:30. Three EC towers are in the Majadas de Tiétar (FLUXNET IDs are ES-LM1, ES-LM2, and ES-LMa, respectively) and an EC tower in the La Albuera (FLUX ID: ES-Abr), respectively (not shown). The map of Majadas de Tiétar was provided courtesy of the Spanish Program of Aerial Orthophotography. 
Revised Figure 2 and its caption:
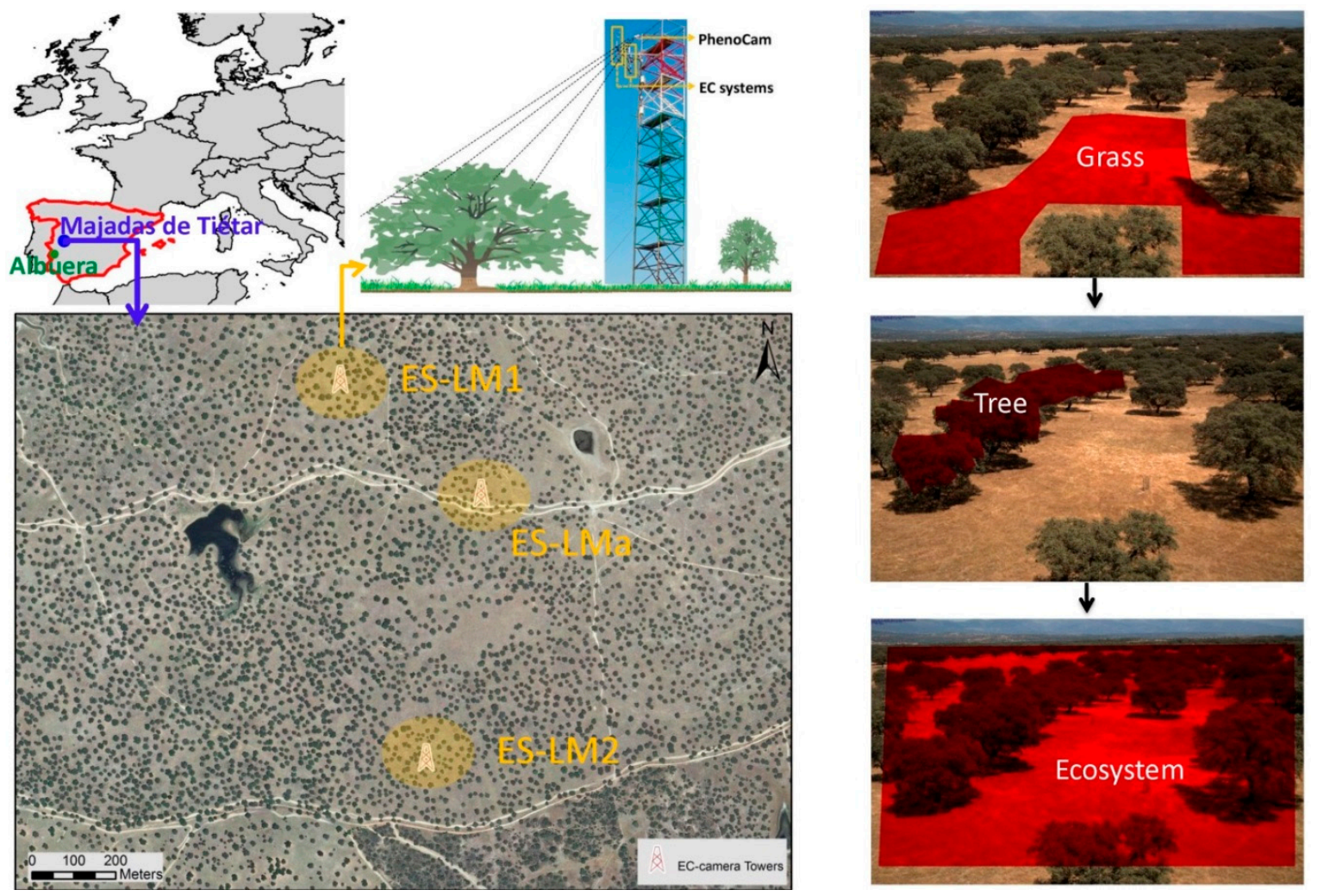

Figure 2. (left panel) Experimental setup at Majadas de Tiétar and La Albuera in Spain and (right panel) an example of regions of interest (ROIs) in each experimental site: Grass, Tree and Ecosystem ROIs, respectively. At each site, an eddy covariance (EC) system was installed at a height of $15 \mathrm{~m}$ to measure the fluxes of the whole ecosystem. A near-infrared-enabled camera was installed at $15 \mathrm{~m}$ beside the EC system to take pictures half-hourly between 10:00 and 14:30. Three EC towers are in the Majadas de Tiétar (FLUXNET IDs are ES-LM1, ES-LM2, and ES-LMa, respectively) and an EC tower is in the La Albuera (FLUX ID: ES-Abr), respectively (not shown). The map of Majadas de Tiétar was provided courtesy of the Spanish Program of Aerial Orthophotography. The design of the schematic plot of instruments in the experimental sites refers to [17] and the photo of the EC tower inside the graphic was taken by T.S. El-Madany.

The above changes do not affect the scientific results. The manuscript will be updated and the original will remain online on the article webpage, with a reference to this correction. The authors would like to apologize for any inconvenience caused.

\section{References}

1. Luo, Y.; El-Madany, T.S.; Filippa, G.; Ma, X.; Ahrens, B.; Carrara, A.; Gonzalez-Cascon, R.; Cremonese, E.; Galvagno, M.; Hammer, T.W.; et al. Using Near-Infrared-Enabled Digital Repeat Photography to Track Structural and Physiological Phenology in Mediterranean Tree-Grass Ecosystems. Remote Sensing 2018, 10, 1293. [CrossRef]

2. Wolf, S. Carbon Dioxide and Water Vapour Fluxes of Tropical Pasture and Afforestation: Seasonal Variations of Net Ecosystem Exchange and Carbon Sequestration Potentials. Ph.D. Thesis, ETH Zurich, Zurich, Switzerland, 2010; p. 163.

(C) 2019 by the authors. Licensee MDPI, Basel, Switzerland. This article is an open access article distributed under the terms and conditions of the Creative Commons Attribution (CC BY) license (http:/ / creativecommons.org/licenses/by/4.0/). 